\title{
Grasping the Knowledge Convergence and Divergence in a Heterogeneous Team
}

\author{
Han-Chang Ling, Chao-Tung Wen, Hsueh-Liang Fan
}

\begin{abstract}
Institutions today are more motivated to organize individuals with distinct talent to create innovations through knowledge integration and differentiation. But a smart team does not warrant performance. Previous researches have indicated that team members must jointly develop a shared mental model (SMM) so that their actions are effectively coordinated and innovations are induced. However, little is known about the mechanism how team SMM improves performance. This research conducted a case study to explore the processes by which SMMs were developed in a heterogeneous team. The results of this study show that team SMM is linked to team performance through both knowledge convergence and divergence. Team SMMs are hierarchically structured so that subordinate SMMs help team efficiency based on converged knowledge. With higher level SMM in effect, heterogeneous team benefits from knowledge divergence from the interplay between subordinate SMM and the adjacent superordinate SMM; the interplay establishes a team-level flow that auto-propels the team toward better outcome without outside interventions.
\end{abstract}

Keywords - shared mental model, heterogeneous team, team innovation process, knowledge sharing

\section{Introduction}

It has become a popular practice for organizations to organize different experts as a heterogeneous team to develop innovative products, processes, services, or business models to achieve a sustainable competitive advantage in the market. Members with distinct knowledge or skills working collaboratively to achieve novel and valuable team goals through continuous transferring ideas and knowledge is desirable but does not necessarily occur[1]. Only when the members consciously and jointly learn to coordinate their talents and efforts will knowledge be shared and hence team performance improved [2]

Previous literature has suggested the important role of a shared mental model (SMM) in the complex processes of team learning[3-7]. When SMM becomes significant, team members hold a common understanding of how the team works as a holistic system; they are more consistent concerning the characteristics of the task, the availability and distribution of tangible and intangible resources, an agreed strategy to achieve the task goal, and how team members behave interactively[8]. In consequence, team members more readily adapt their respective activities to the internal and external requirements.

\section{Han-Chang Ling}

Chao-Tung Wen

National Chengchi University

Taiwan

Hsueh-Liang Fan

National Taiwan University

Taiwan
In orthodox SMM studies, knowledge convergence is implied; team SMM was conceptualized as similarity among members' mental model. This conceptualization is logical when research focus is on the linkage between SMM and performance indexed by efficiency or fluency. However, SMM was assumed to be a bulk of mental model whereas shared knowledge in a business work team is likely to be more sophisticated. Therefore, it is desirable to inquire the mechanism by which converged SMM helps team efficiency. In addition, the knowledge creation perspective of SMM was largely ignored. In other words, the way teams benefit from divergent interactions was generally overlooked whereas diversity is an important motivation to organize a heterogeneous team. It is thus desirable to ask how heterogeneous team members make their respective tacit knowledge shared among others and thereby solicits innovative ideas.

To address the above question, this study used a case study approach to an innovation process. Investigating the Blossom Project in the Pavilion of Dreams in the 2010 Taipei International Flora Exposition, we restructured the Project into episodes according to the initial discussion and the following design changes. These episodes were then categorized based on the associated SMM so that the pattern of their interrelationship could shed some light on our understanding of the structure of SMM in this heterogeneous team. Further analyzing this structure helps explaining how knowledge convergence and divergence each improves team performance in a different but integrated way.

\section{Literature Review}

Developing shared mental model is a key to team learning[5]. Once team members develop SMMs to a sufficient extent, they hold similar understanding of how the team performs as a holistic system. In such a state, team members have a shared knowledge on what the team goal is about and the strategy to that goal, i.e. the taskwork. Also shared among members is the way they interact, i.e. the role/responsibility distribution or the teamwork. With high level of similarity on taskwork and teamwork, individual talent and effort can be oriented and integrated toward the team goal, thereby resulting in better performance.

A typical empirical research on team SMM is conducted as follows. Participating students are organized into groups of two or three. Then, participators are trained on a computerized simulation game, e.g., aviation, combat, or business decisions, for basic skills. After a period of time, each participator is solicited for his/her knowledge of the task, the status quo, and/or other teammates' expected actions. Similarity among team members' solicited knowledge is contrasted with the performance, as represented by the game score. The pairs of cognitive similarity and performance are then analyzed to infer the relationship between team SMM and performance. Other field studies investigated cockpit crews, aviation control 
teams, or sports teams with similar method[9-11]. These previous researches commonly concerned how similar the mental model teammates hold and how this similarity contributes to the team performance. The underlying logic is that convergence helps team functioning.

Though the linkage between cognitive convergence and team performance provided fruitful insight on how team SMM improves team efficiency, little is known about the mechanism in between. In addition, the value associated with divergence in the SMM development process is largely ignored. Researchers paid less attention to the process before a concrete SMM is formed. This process is worthy of exploring because it is the stage where different knowledge encounter and innovations are expected. Therefore, the research question of this study is how a team benefits from both knowledge convergence and knowledge divergence when building SMM

\section{Methods}

The case study method is used in this exploratory research $[12,13]$. We used the critical incident technique to partition the project into episodes divided by engineering changes[14]. Team members shared similar mental models within each episode; each engineering change represents a transition into a different episode and associated team SMM.

We collected data from the Blossom Project in the Pavilion of Dreams in the 2010 Taipei International Flora Exposition. Running for twenty-three months from November 2008, Blossom Project was expected to produce a mechanical flower as a prelude that tells an eco-story by technological language. Therefore, the mission was an integration of creativity and technology for an outcome of a virtual artistic journey laden with wondrous surprises. The resulting six-meter diameter flower was suspended upside down from the ceiling and comprised 120 sets of plastic petals that are arranged in three layers. Each of the petals is moved by a string and its associated motor. The strings and motors are in turn programmed by a controller to allow for sophisticated simulation of the blooming rhythm of a flower.

This case fits the study requirements because (1) this project requires collaborations among members with quite different domains so that integrating distant cognitions is imperative for goal achievement; (2) the team members did not know each other before they were recruited and hence must start from scratch; and (3) the end result was drastically different from the original plan.

We interviewed five domain representatives and two administrators for an average of seventy-four minutes each. The interviews were recorded and dictated. The team comprised experts of the five distinct domains and different institutes. The members did not know each other before they joined this project team. Yu (an artist), Teng (an engineer), and Fan (a theatre technique) were involved from the beginning; Huang (a spatial design) and Pan (a interface control) joined six months later. Executive Producer and Exhibition Director Chang held the official meetings where major decisions were made. Daily operations were coordinated by Exhibition Content Supervisor Lee.

Because the critical incident technique relies heavily on responders' memory and is hence vulnerable to blurred imprecision or self-serving bias, we used archive data and follow-up emails for cross triangulation or clarification. In emails, interviewees were asked of alternative questions or ranking among alternatives. It took eight months for the interviews and triangulations since August 2014. Episodes were then arranged according to their attributes, timing and duration.

\section{Iv. Findings}

We identified twenty-one episodes based on the initial interactions and engineering changes. These twenty episodes were categorized into eight groups $\mathrm{A} \sim \mathrm{H}$ according to the nature of each episode. In addition, an unrealized attempt was also found during the interview. These episodes are described as follows and illustrated in Fig. 1 in groups and levels.

\section{A. The Flower}

$\mathrm{Yu}$, an artist, first presented his idea to the team by drawings. Suspended upside down from the ceiling, the flower extends for twelve meter and is composed of 120 sets of plastic petals arranged in three layers. Said petals are designed to be hauled by a centralized motor through strings to simulate the blooming of a flower. However, engineer Teng was not touched.

“...kept silent and shrank back from the conference table all the way through the meeting. Nothing left in my brain when leaving the meeting room".

$\mathrm{Yu}$ then returned and made a prototype with paper petals, fishing string, and LOGO motor and gears. Although that prototype got stuck during the demonstration in the next meeting, it ignited the sense making of other members. Other team members started asking questions and raised counterproposals. For example: how about put the flower on the floor instead of hanging upside down? This arrangement is safer, cost effective, and easier for maintenance. But, this proposal was rejected by $\mathrm{Yu}$ :

"This flower is intended to make audience feel as tiny as an insect like bees or butterflies. This feeling help the audience getting into a mood for the following ecoexperience."

Other proposals included (a) a smaller flower for easier handling and lower cost; (b) applying ultraviolet-sensitised dye; and (c) pivotal motor driving instead of string hauling. The discussions came to an agreement substantially the same as the original proposal except for a compromised size of six meter. The team proceeded with the project according to said agreement; none of these rival proposals popped up again throughout the project.

\section{B. The Presentation}

There were two episodes in regard to how the flower presents: simplex exhibit (B-1) and complex performance (B-2). The transition was due to team goal change; curators required the flower to perform agilely for different scenarios. Neither episode overrules the premises defined by episode (A). 


\section{Driving Mechanism}

Parallel to the complex performance requirement as described in (B), two new members, Huang and Pan, were introduced to the team with an alien technology, Digital Multiplex DMX512. DMX512 is a matured technology widely used in concerts or theatres to control hundreds of lights from a lighting console. But incumbent members did not aware it. Huang or Pan had no experience using DMX512 for mechanical control either. However, this new solution of DMX512 triggered a swift transition of the driving mechanism from centralized $(\mathrm{C}-1)$ to decentralized (C-2). The team welcomed such a solution because it not only met the new requirements but also relieved the previous engineering concerns. Engineer Teng summarized: "the likelihood of success is less than half without this transition."

\section{Cycle Time}

The cycle time for the flower opening and closing was initially set to $90 \mathrm{~s}$ (D-1). When this target was achieved, the artist proposed a more sophisticated program demanding shorter cycle time. The shorter cycle time was again realized. This iteration repeated itself, thus stepwise driving the cycle time further to $30 \mathrm{~s}, 20 \mathrm{~s}, 15 \mathrm{~s}$, and finally $10 \mathrm{~s}$ (D5).

\section{E. Hauling String}

Steel wire (E-1) was naturally selected to move the petals. When engineer Teng found that steel wire twists would interfere with the petal positions, engineers switched to plastic fishing string (E-2) without consulting to others. When the cycle time was shortened, positioning precision became a problem and drove Teng and Pan to change to cloth fishing string (E-3).

\section{F. Driving Motor}

A step motor (F-1) was first selected and then substituted with a more expensive direct current brushless motor (F-2) because of noise intolerance and the higher speed requirement.

\section{G. Startup Scheme}

The 120 petals were originally designed to start moving simultaneously (G-1). When the flower was moved into the venue, the team found that the surge current required was beyond the site capacity. Pan solved this problem by starting the petals in batches with $10 \mathrm{~ms}$ separations (G-2).

\section{H. Maintenance Plan}

Engineers had supposed that the system would not require maintenance during the exhibition (H-1). However, along with the shorter cycle time and more sophisticated performance, parts wearing problem emerged. In response, Teng prepared a periodic maintenance plan $(\mathrm{H}-2)$. The team increased the maintenance frequency $(\mathrm{H}-3)$ to deal with further demand.

\section{An Unrealized Attempt}

With the single module tested and other 119 modules copied and assembled, the team welcomed the first successful integrated test. The flower "danced" smoothly. Artist $\mathrm{Yu}$ was also happy to see the technical advancement far beyond his expectation. Yu recalled:

"when driving back home in hills where thunderstorms are frequent, an idea came to my mind: why not let the flower make a shake with a thunder?'

Other team members were surprised but did not exclude this idea. They evaluated this proposal and found that such abrupt movements would exert additional stress far beyond the original system architecture. Further investing time and money in the components would not work. This idea was thus dropped.

These eight groups can be further hierarchically classified into four levels I IV as also shown in Fig. 1. Episode A in level I depicts the product concept. Episodes B and $\mathrm{C}$ in level II are characterized by strategy. In level III, episode D represents performance and engineering specifications. Episodes $\mathrm{E} \sim \mathrm{H}$ in level IV are technical solutions. Each superordinate level functions as both a foundation for and also a frame within which subordinate levels are formed.

\section{v. Discussion}

This study illustrates how SMMs were developed in a heterogeneous work team. The hierarchical structure of the episodes and associated SMM helps better understand how knowledge convergence and divergence contribute to team SMM processes and performance.

First, knowledge convergence facilitates SMM developmental processes in a hierarchical way; superordinate SMM provides an assured room in which subordinate SMMs are formed without having to looking back or around. Consequently, decision speed and quality are advanced.

In line with what previous scholars have suggested, each SMM development of this study comprised activities characterized by new knowledge sharing, co-construction, and constructive conflicts[15]. But debates and conflicts became less obvious or less frequent not only at latter stages but also during subordinate SMM developments. Although 


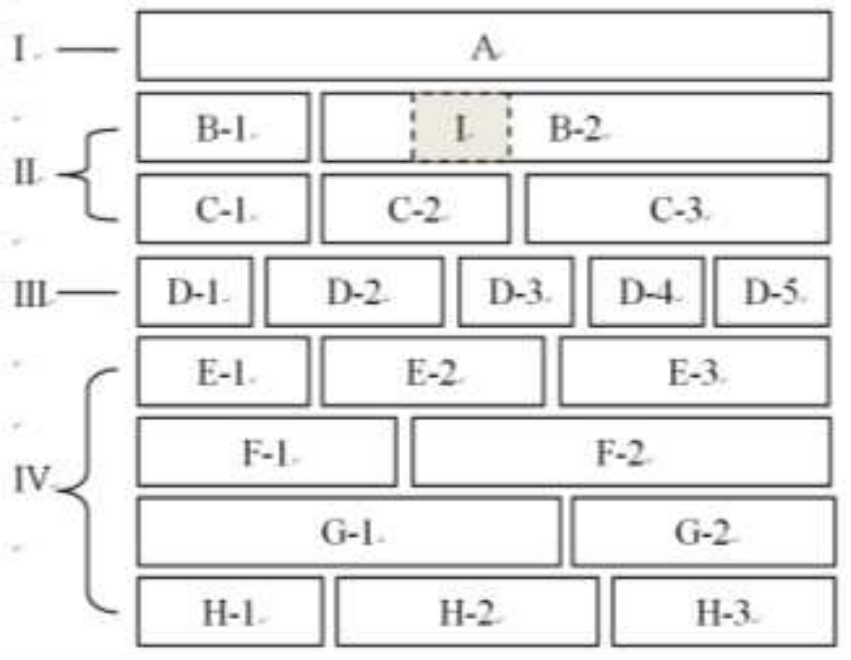

Figure 1. Episodes in eight groups and four levels

transitions were frequent in episodes E-H at level IV, argues were rather rare. Sometimes, a transition decision was made by solely one domain group, mostly engineering team, without consulting to other members. This evidenced the existence and function of team SMM that actions are taken without redundant coordination or confirmation[3].

Thus, this study supports the linkage between team SMM and performance. In the meantime, the hierarchical structure found in this research makes the mechanism how team SMM helps performance clearer. Similar framing effect and decision making pattern could be found when referring to dominant design[16] and architectural innovation[17].

Second, knowledge divergence can be a continuous process that auto-propels the team toward transiting to more challenging goals. In episodes D at level III, the cycle time was squeezed from the initial 90 second to the final $10 \mathrm{~s}$ with four steps. No one had envisioned such advancement in the beginning. Rather, the scenario was that when a previous agreed target was engineering attained, the artist proposed an even more demanding goal which was again achieved. These iterations reflect the dynamic nature of team knowledge reservoir. In this Blossom project, engineering achievements expanded the imaging space where the artists can envision more sophisticated programs. The new programs in turn push a more demanding specification. This interplay between challenge and skill constitutes a zigzag trajectory similar to that in the flow theory[18]. As such, we conjecture that flow can be a team level phenomenon that auto-propel the team toward better outcome without outside interventions.

The unrealized proposal episode I demonstrated a situation that challenge transcended skill and thus declined. But this proposal neither emerged from vacuum nor preexisted in the artist's mind. It was also triggered by engineering achievement at that stage instead.

\section{vI. Practical Implication}

The main implication for project managers is a stagewise tight and loose management. Project managers are advised to be more involved in the formation of superordinate SMMs from the very beginning. The frame that upper level SMM provides should be narrow enough to match the project interests but wide enough to accommodate knowledge interplay in the subordinate SMMs. When the frame comes to in effect, a project manager can leave room for team members to establish a team-level flow.

\section{Limitations and Directions for Future Research}

This study selected the critical incident technique to rebuild the project scenarios. For all the triangulation efforts made, the retrospective nature of the critical incident technique remains a disadvantage; the ex post facto rationale can therefore be challenged. As such, participant observation might be recommended for future researches such that the ex ante prediction can provide falsification openings. In addition, the Blossom is a de facto project team in which members with extremely distant cognitions were alien to each other. A more popular setting, such as a new product/service/process development project in a firm, is likely to provide generalization opportunities.

After the text edit has been completed, the paper is ready for the template. Duplicate the template file by using the Save As command, and use the naming convention prescribed by your conference for the name of your paper. In this newly created file, highlight all of the contents and import your prepared text file. You are now ready to style your paper; use the scroll down window on the left of the MS Word Formatting toolbar.

\section{Conclusion}

The results of this study showed that team SMM is linked to performance through a hierarchical mechanism. Moreover, we conjecture that with superordinate SMM in effect, interplay among heterogeneous team members in subordinate SMMs establishes a team-level flow that autopropels the team toward better outcome without outside interventions.

\section{References}

B. Nooteboom, W. Van Haverbeke, G. Duysters, V. Gilsing, and A. van den Oord, "Optimal cognitive distance and absorptive capacity," Research Policy, vol. 36, pp. 1016-1034, Sep 2007. B. Barron, "When Smart Groups Fail," The Journal of the Learning Sciences, vol. 12, pp. 307-359, 2003.

J. A. Cannon-Bowers and E. Salas, "Reflections on shared cognition," Journal of Organizational Behavior, vol. 22, pp. 195-202, Mar 2001.

L. A. DeChurch and J. R. Mesmer-Magnus, "Measuring Shared Team Mental Models: A Meta-Analysis," Group DynamicsTheory Research and Practice, vol. 14, pp. 1-14, Mar 2010. E. Salas, D. E. Sims, and C. S. Burke, "Is there a "Big Five" in Teamwork?," Small Group Research, vol. 36, pp. 555-599, October 1, 20052005

S. Mohammed, L. Ferzandi, and K. Hamilton, "Metaphor No More: A 15-Year Review of the Team Mental Model Construct," Journal of Management, vol. 36, pp. 876-910, Jul 2010.

S. E. Humphrey and F. Aime, "Team Microdynamics," Academy of Management Annals, vol. 8, pp. 443-503, Jan 2014. 
Proc. of The Fourth Intl. Conf. On Advances in Economics, Management and Social Study - EMS 2015

Copyright (C) Institute of Research Engineers and Doctors, USA .All rights reserved.

ISBN: 978-1-63248-071-2 doi: 10.15224/ 978-1-63248-071-2-31 mental models in expert team decision making," in Individual and group decision making: Current issues, N. J. Castellan Jr., Ed., ed NJ: Lawrence Erlbaum: Hillsdale, 1993, pp. 221-246.

[9] J. Orasanu, "Shared mental models and crew decision making," U. D. o. Transportation, Ed., ed. Jupiter, Florida, US: Advanced Aviation Concept, Inc., 1992.

[10] K. A. Smith-Jentsch, J. E. Mathieu, and K. Kraiger, "Investigating linear and interactive effects of shared mental models on safety and efficiency in a field setting," Journal of Applied Psychology, vol. 90, pp. 523-535, May 2005.

[11] E. Salas, M. A. Rosen, C. S. Burke, G. F. Goodwin, and S. M. Fiore, "The Making of a Dream Team: When Expert Teams Do Best.," in The Cambridge Handbook of Expertise and Expert Performance., K. A. Ericsson, et al., Ed., ed, 2006, pp. 439-454.

[12] R. A. Wolfe, "ORGANIZATIONAL INNOVATION REVIEW, CRITIQUE AND SUGGESTED RESEARCH DIRECTIONS," Journal of Management Studies, vol. 31, pp. 405-431, May 1994.

[13] R. Yin, Case Study Research: Design and Methods. Newburry Park.: Sage Publications., 1994.

[14] J. C. Flanagan, "THE CRITICAL INCIDENT TECHNIQUE," Psychological Bulletin, vol. 51, pp. 327-358, 1954

[15] S. Decuyper, F. Dochy, and P. Van den Bossche, "Grasping the dynamic complexity of team learning: An integrative model for effective team learning in organisations," Educational Research Review, vol. 5, pp. 111-133, 20102010.

[16] J. M. Utterback and W. J. Abernathy, "A dynamic model of process and product innovation," Omega, vol. 3, pp. 639-656, $12 / / 1975$.

[17] R. M. Henderson and K. B. Clark, "Architectural Innovation: The Reconfiguration of Existing Product Technologies and the Failure of Established Firms," Administrative Science Quarterly, vol. 35, pp. 9-30, 1990.

[18] M. Csikszentmihalyi, Creativity: Flow and the Psychology of Discovery and Invention. NY: HarperCollins, 1996. 